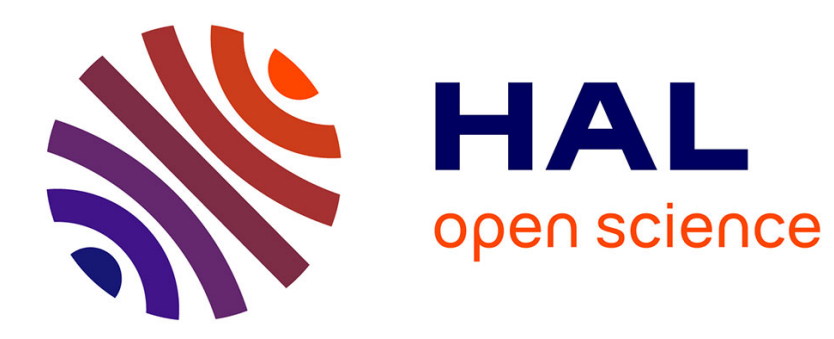

\title{
Fatigue damage mechanism and strength of woven laminates
}

\author{
J. Xiao, C. Bathias
}

\section{To cite this version:}

J. Xiao, C. Bathias. Fatigue damage mechanism and strength of woven laminates. Journal de Physique IV Proceedings, 1993, 03 (C7), pp.C7-1651-C7-1656. 10.1051/jp4:19937258 . jpa-00251897

\section{HAL Id: jpa-00251897 https://hal.science/jpa-00251897}

Submitted on 1 Jan 1993

HAL is a multi-disciplinary open access archive for the deposit and dissemination of scientific research documents, whether they are published or not. The documents may come from teaching and research institutions in France or abroad, or from public or private research centers.
L'archive ouverte pluridisciplinaire HAL, est destinée au dépôt et à la diffusion de documents scientifiques de niveau recherche, publiés ou non, émanant des établissements d'enseignement et de recherche français ou étrangers, des laboratoires publics ou privés. 


\title{
Fatigue damage mechanism and strength of woven laminates
}

\author{
J. XIAO and C. BATHIAS \\ ITMA, Department of Industrial Materials, CNAM, 2 rue Conté, 75003 Paris, France
}

\begin{abstract}
The apparent secant stiffness changes with the cyclic number for both unnotched and notched woven laminated specimens (two orthotropic and one quasi-isotropic) during tensile fatigue test at a fixed ratio of maximum fatigue load to UTS were observed. The observable damage initiation and evolution as a function of the cyclic number were directly measured at the notched specimen surface with a video-camera system. The fatigue strengths of the unnotched and notched specimens were determined. The results show that the normalized apparent secant stiffness change curves as a function of cyclic numbers can be divided into three stages. For the first and the second stages in notched specimens and for total life of unnotched specimens, the damage has not been evidently observed and certainly verified with the traditional experimental methods such as radiography and microscopy although many acoustic emission signals can be obtained. The last stage for the notched specimens (N/Nf $>0.4$, the secant stiffness decreases fast) corresponds to the initiation and evolution of the observable damages. The fatigue strength of these woven composite laminates is dominated by the third stage during which the observable damage develops along the specimen ligament until fracture. During the third stage, a critical dimension at the specimen ligament and a life threshold can be found beyond which a final catastrophic fracture will immediately occur. The quasi-isotropic laminate is of a fatigue strength lower than the two orthotropic laminates of which the fatigue strengths are approaching to each other. The fatigue life is also influenced by the stacking sequences.
\end{abstract}

\section{INTRODUCTION}

Under cyclic loading, the behaviors for woven glass / epoxy laminates have not been very well understood. In this paper, the fatigue damage and strength of three woven laminates (two orthotropic and one quasi-isotropic) [1] will be discussed. Up to now, due to the complexity for composite materials, a fundamental understanding of the relationship between damage mechanisms and failure modes that dominate the composite fatigue behavior has not yet been established. Most studies on composite material fatigue behaviors have been carried out only with the help of phenomenological methods. To predict fatigue life and residual strength, several statistic models [2-7] were proposed. The parameters in these models, obtained with certain statistic methods, for example, the maximum likelihood estimation, are not easy to be determined because it is necessary to have a number of specimens. Especially, the notched laminate fatigue residual strength does not always vary monotonically with the number of cycles [8]. As pointed in [9], it can not be preferably chosen as a parameter describing characteristically the damage mechanisms. Therefore, some researchers considered the apparent secant stiffness changes as the parameters demonstrating damage mechanisms [10-11] and measured these changes under different test conditions [12-14]. In the present paper, at a fixed cyclic load level, the apparent secant stiffness changes as a function of the cyclic number for both unnotched and notched woven composites were measured. The damage initiation and evolution in the laminates were observed. The fatigue life, strength and their influence factors for the laminates are also studied. 


\section{MATERIALS AND EXPERIMENTS}

The stacking sequences and the thicknesses for the three woven laminates studied in this paper are shown in Table.1. The warp and woof compositions in the woven ply of the laminates are respectively $82 \%$ and $18 \%$. The properties for the woven lamina, the methods to fabricate the specimens and to measure the ultimate static strength were shown in [1].

Table.1 Stacking sequences and thicknesses of three woven laminates studied in the paper

\begin{tabular}{|c|c|c|c|}
\hline TYPE & DESCRIPTION & STACKING SEQUENCES & THICKNESS \\
\hline Glass-1 & E Glass-weave/Epoxy & {$[0 / 0 /+45 / 0 / 0 /-45 / 90 / 90] \mathrm{s}$} & $3.3 \mathrm{~mm}$ \\
\hline Glass-2 & E Glass-weave/Epoxy & {$[0 /+45 / 0 / 90 / 0 /-45 / 90 / 0] \mathrm{s}$} & $3.3 \mathrm{~mm}$ \\
\hline Glass-3 & E Glass-weave/Epoxy & {$[0 / 0 /+45 /+45 /-45 /-45 / 90 / 90] \mathrm{s}$} & $3.3 \mathrm{~mm}$ \\
\hline
\end{tabular}
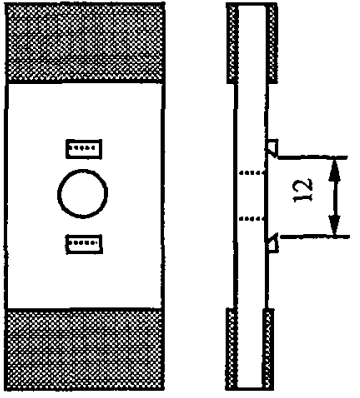

(a)

Apparent secant stiffness measurement

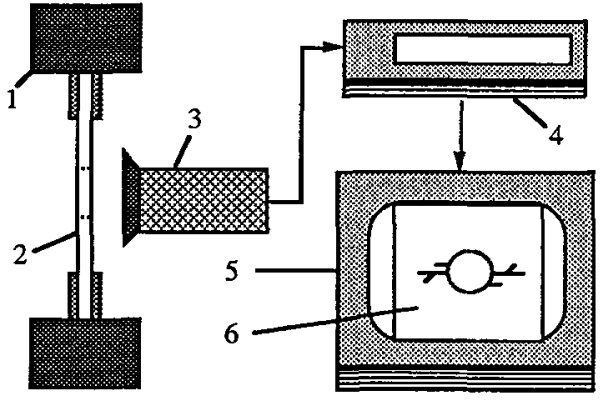

(b) Observation of damages at the specimen surfaces

1.Machine 2. Specimen 3.Camera

4.Magnetoscope 5.Television 6. Specimen image

Fig.1 Measurement of apparent secant stiffness and observation of damage at the specimen surfaces

The apparent secant stiffness changes were measured with a gage-length extensometer centered to the notch (Fig.1(a)). The static secant stiffness for unnotched and notched specimens was periodically determined by interrupting the fatigue tests and by measuring the curves of load vs extensometer strain up to the maximum fatigue loads. The observable damage initiation and evolution were directly measured at the notched specimen surface with a video-camera system (Fig.1(b)), and were verified by X-radiography photos. The tensile fatigue tests of the unnotched specimens and notched specimens with a diameter of 5 mm were carried out with INSTRON machine at room temperature, and with a frequency of $20 \mathrm{~Hz}$, a sine wave. Relevant data were acquired by a system piloted with PC-IBM. The acoustic emission was used to detect the damages during the fatigue tests. The stress ratio is equal to 0.1 and the ratio of the maximum fatigue load to UTS is equal to 0.5 .

\section{RESULTS AND DISCUSSIONS}

\section{Secant stiffness changes}

The normalized secant stiffness changes as a function of both unnotched and notched normalized fatigue lives for the laminates have been respectively measured. These measurements indicate that unnotched and notched specimens tend to go through three stages during the fatigue tests. Figs.2a to $2 \mathrm{c}$ show a result comparison between the unnotched and notched specimens respectively for the three laminates. From these figures, it can be seen that the first stage is characterized by a rapid stiffness loss during a short life, and in the second stage the stiffness degradation is much more gradual and takes place over a much longer proportion of the life. During the third stage, the notched stiffness degradation either is much more rapid (Glass-1 and 2) or is much earlier (Glass-3) than the unnotched specimens.

Figs.3a and $3 \mathrm{~b}$ show a comparison of the normalized secant stiffness change vs normalized cyclic number among three different stacking sequences respectively for the unnotched and notched specimens. Three stages at the normalized stiffness curve for the quasi-isotropic laminate are much more evident than those 
for the two orthotropic laminates. The orthotropic laminate Glass- 2 (the $90^{\circ}$ plies are separated by the other plies) possesses a greatest residual stiffness and the quasi-isotropic laminate (the fraction of $0^{\circ}$ plies is less than that in the others) is of the least residual stiffness, both for unnotched and for notched specimens. A microscopic examination shown in [15] can explain these differences.
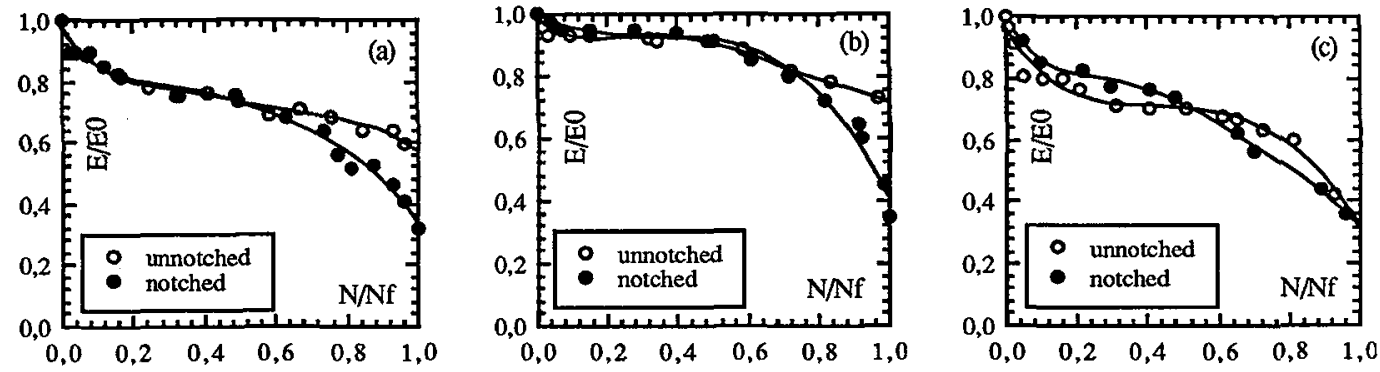

Fig. 2 Comparison of the normalized secant stiffness changes vs the normalized cyclic numbers between the unnotched and notched specimens: (a) Glass-1; (b) Glass-2; (c) Glass-3

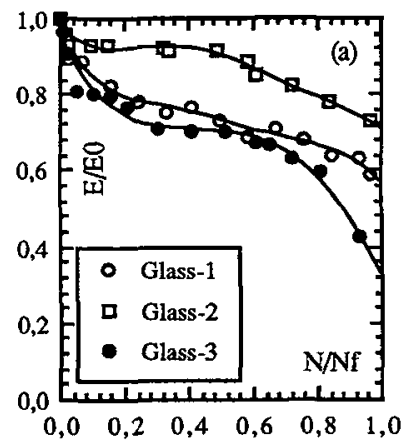

Fig.3 Comparison of the normalized secant stiffness changes vs the normalized cyclic numbers between different stacking sequences:

(a) unnotched specimens, (b) notched specimens

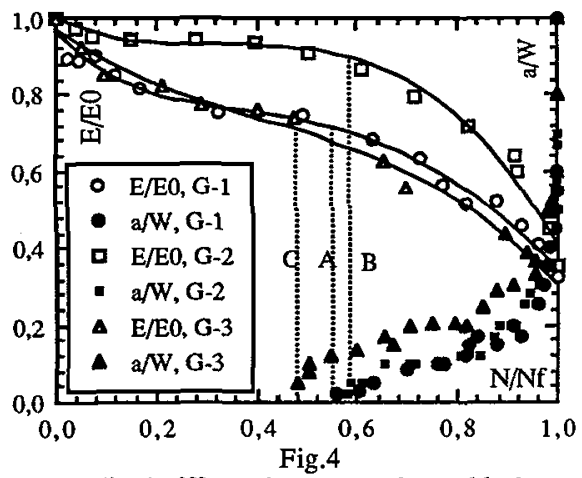

Normalized stiffness decrement, observable damage initiation and evolution with the cycle number

\section{Initiation and evolution of observable damages}

The normalized apparent secant stiffness change, E/E0, and the size of observable damage region, a, observed at the notched specimen surface were measured at the same time. The latter is normalized by the half specimen width, W. The results obtained have been shown in Fig.4. The third stage at the normalized apparent stiffness change curves corresponds to the initiation and the evolution of the observable damages, respectively indicated by the three dotted lines A, B and C in Fig. 4 for the three laminates. These damages are characterized by the cracks in the plies to $90^{\circ}$, produced adjacent to the hole and contaminating the other plies with a very rapid rate and evolving along the ligament, as indicated in [16]. As concerns the first and the second stages for the notched specimens and the total life for the unnotched specimens, it must be mentioned that the damages produced in the materials are not visually observable at the surfaces but it is certain that many micro-level damages, for example, micro-cracks produced in the resin of interweaving structure and decohesions produced at the interfaces between the resin and the fiber, occur in the materials because many signals can be observed at the acoustic emission scheme during these two stages. But, as indicated in [1], these damages have not been verified by microscopy and X-radiography, even with certain opacities to X-ray, as iodide zinc and tetrabromoethane. It can be seen from Fig.4 that the observable damages initialize much earlier in the laminate Glass-3 than in the others (Glass-1,2); by contrast, they initialize much later in Glass-2 than the others (Glass-1,3). For a same life fraction, it is Glass-3 (quasiisotropic) that is of a greater damage zone size, as verified with X-radiography photos in Fig. 5 . The damage observed at the notched specimen surface has been shown in [15]. During the fatigue tests, any evident delamination adjacent to the free-edges can not be observed in the laminates. A critical dimension of damaged region along the notched specimen ligament and a critical value of the normalized life can be determined, as shown in Fig.6. Beyond these critical values, a final catastrophic fracture will occur immediately. 

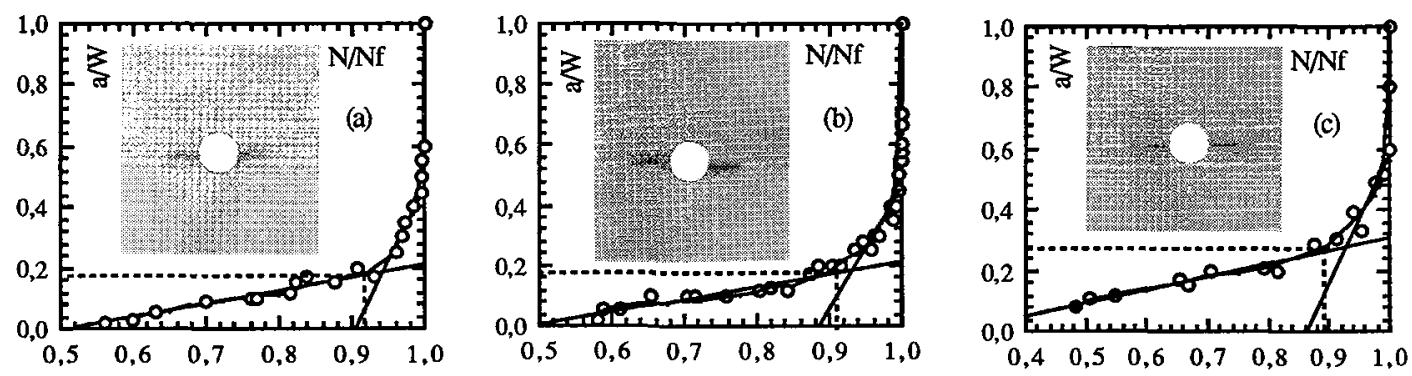

Fig.5 Evolution at the specimen surface of observable damages: (a) Glass-1; (b) Glass-2; (c) Glass-3

\section{Fatigue strength and life}

Figs.6a and $6 \mathrm{~b}$ show respectively an unnotched and notched fatigue strength comparison among the three different stacking sequence laminates. It can be seen that, as for static tensile strength, one can not observe a significant fatigue strength difference between the two orthotropic laminates (Glass-1 and 2) although Glass- 1 is favorable for delamination, and that Glass- 3 is of a fatigue strength much lower than the Glass-2 and 3 because of its lower fraction of the plies to $0^{\circ}(25 \%)$ than the two others $(50 \%)$.

Figs.7a and $7 \mathrm{~b}$ show respectively an unnotched and notched fatigue strength comparison among the three different stacking sequence laminates at the same ratios of the maximal fatigue stress to UTS. It seems that the Glass-2 is of a lightly longer fatigue life than the two others, in special, at lower stress levels. A microscopic observation can show the damage evolution in the laminates. One can see from Fig.7 in [15] that the damage propagation must overcome much more obstacles paid by the interfaces between the plies to $90^{\circ}$ and the other plies in Glass-2 than in the other laminates so that the route passed by the damage propagation in this laminate is much more sinuous than that in the other laminates. This is the reason why this laminate has both a greater residual stiffness during the fatigue tests and a longer fatigue life, as shown in [16].

The notch effect on the fatigue behavior may be discussed. It seems that, at the same ratio of the maximal stress to UTS, for each stacking sequence, the notched specimen has a longer fatigue life than the unnotched specimen, as shown in Figs.8a to 8c. For the three laminates, the notched specimens are of the same ratios of the fatigue strength to UTS as the unnotched specimens, almost equal to 0.40 . The ratios of the notched fatigue strength $\left(\sigma_{\mathrm{d}, \mathrm{N}}\right)$ to the unnotched fatigue strength $\left(\sigma_{\mathrm{d}, \mathrm{o}}\right)$ are respectively almost equal to their static strength reduction factors. It can be considered that the fatigue strength for the Glass- 3 is the most insensible to the hole effect because of its higher value of $\sigma_{\mathrm{d}, \mathrm{N}} / \sigma_{\mathrm{d}, 0}[16]$.
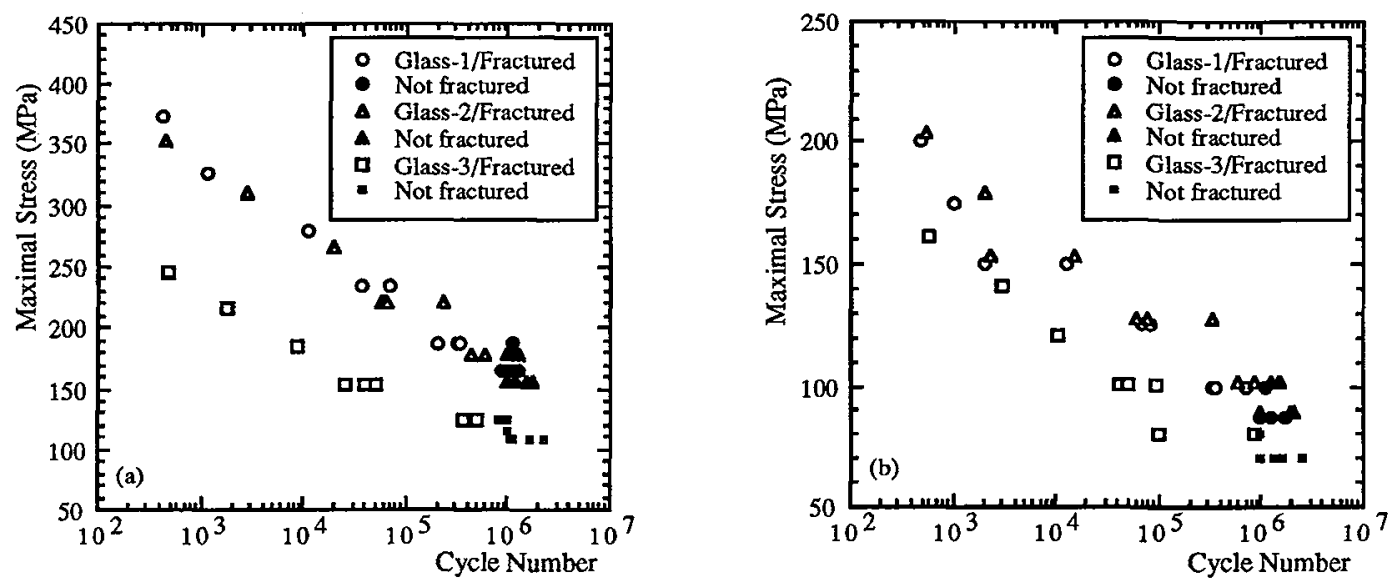

Fig.6 S-N curve comparison (maximal stress vs cycle number): a) unnotched specimen; b) notched specimen 

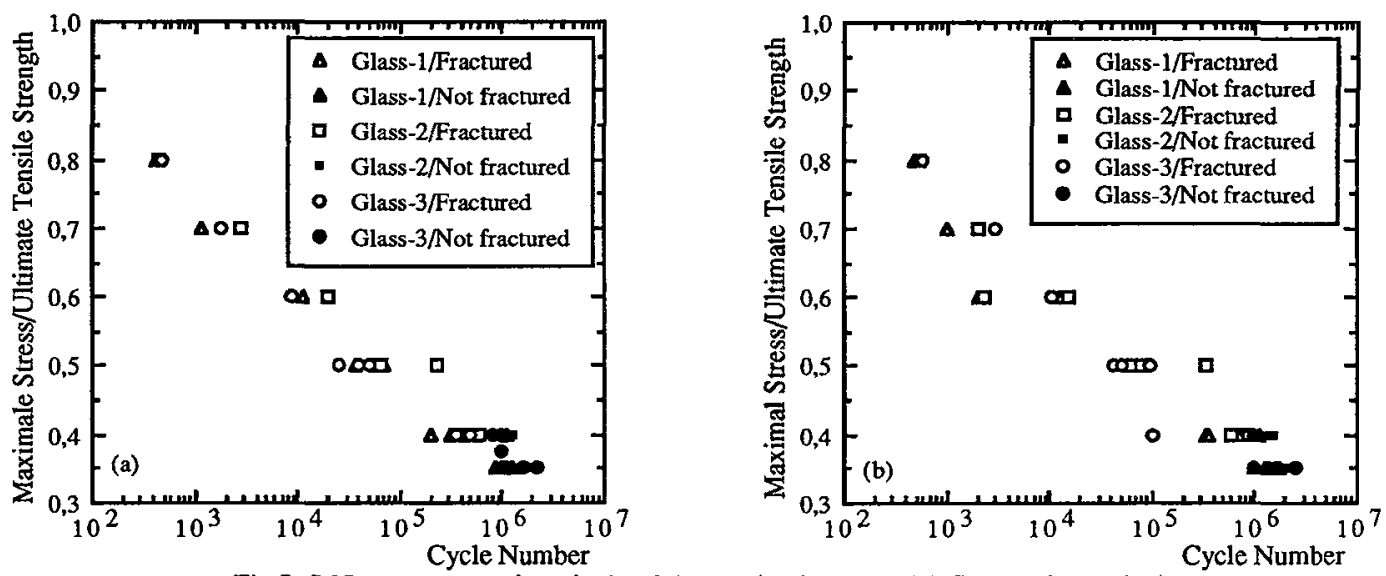

Fig.7 S-N curve comparison (ratio of the maximal stress to UTS vs cycle number):

a) unnotched specimen; b) notched specimen
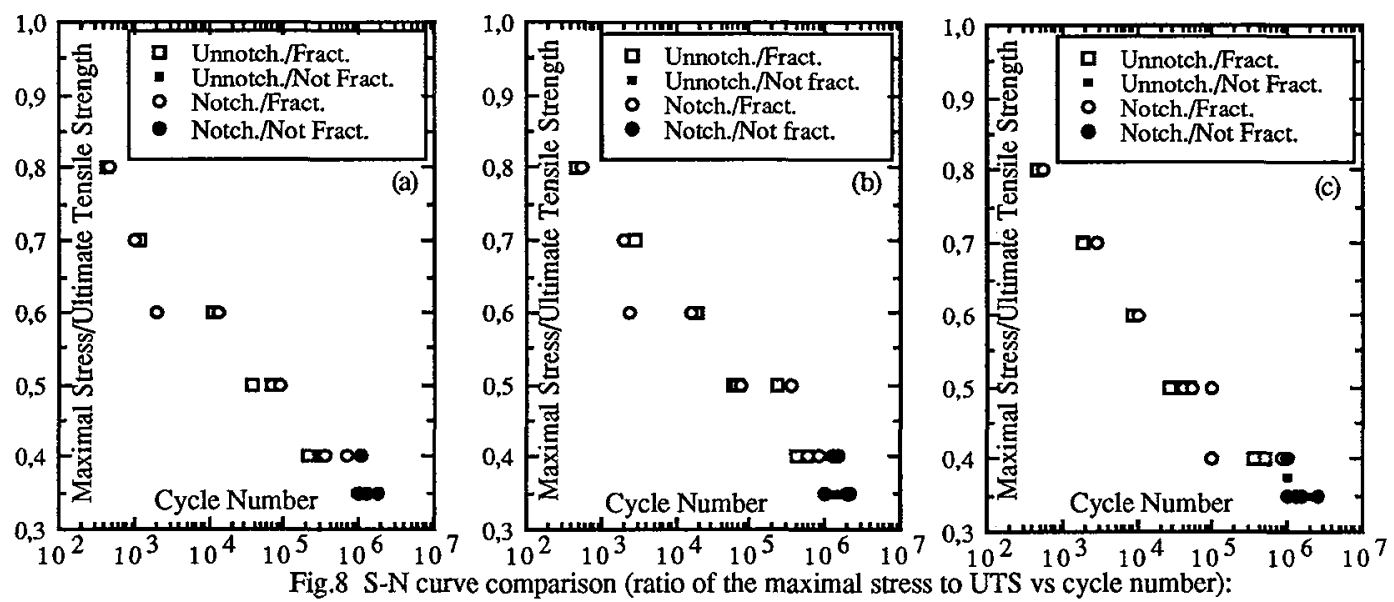

a) Glass-1; b) Glass-2; c) Glass-3

\section{CONCLUSIONS}

The normalized apparent secant stiffness change curves as a function of cyclic numbers can be divided into three stages for three unnotched and notched woven laminates (two orthotropic and one quasi-isotropic).

During the first and the second stages of the apparent secant stiffness changes in the notched specimens and during the total life of the unnotched specimens, damages may be mainly characterized by the microcracks produced in the resin of interweaving structure and decohesions produced at the interfaces between the resins and the fibers because many acoustic emission signals can be observed during these two stages although these signals do not possess a good reproducibility. However, this type of damage has not been evidently observed and certainly verified with the traditional experimental methods such as radiography and microscopy in our study. How to detect evidently and verified certainly these damages is a problem to be solved.

The last stage (N/Nf $>0.4$, the secant stiffness decreases fast) for the notched laminates corresponds to the initiation and evolution of the observable damages in notched specimens. During the last stage, the fatigue damages in the notched specimens were found to be observable directly at the specimen surface with a video camera system. Their propagation is influenced both by the thickness of the continuous plies to $90^{\circ}$ and by the stacking sequences, which has been verified both by microscopy examination and by $\mathrm{X}$ - 
radiography.

On the one hand, the fatigue resistance of these woven composite laminates is dominated by the third stage during which the observable damages develop along the specimen ligament until fracture; during the third stage, a critical dimension at the specimen ligament and a life threshold can be found beyond which a final catastrophic fracture for the specimens will immediately occur. On the other hand, the fatigue resistance of the quasi-isotropic laminate is lower than that of the two orthotropic laminates; but the two different orthotropic laminates have almost a same fatigue resistance; at the same ratios of the maximal fatigue stress to UTS, the laminate having more interfaces between the $90^{\circ}$ plies and the other plies has a longer fatigue life than the others, and the notch permits to obtain a longer fatigue life in this case especially at low fatigue stress levels.

\section{REFERENCES}

[1] J.Y.Xiao, Doctoral Thesis, Dept.Indu.Mate., CNAM, Paris (1992)

[2] H.T.Hahn, R.Y.Kim, J. Composite Materials, vol.9, pp297-311 (1975)

[3] J.N.Yang, M.D.Liu, J. Composite Materials, vol.11, pp176-203 (1977)

[4] J.N.Yang, J. Composite Materials,vol.12, pp19-39 (1978)

[5] J.N.Yang, D.L.Jones, Proceedings of the 3rd ICCM, Held in Paris, pp472-483 (1980)

[6] P.C.Chou, Robert Croman, ASTM STP 674, S.W.Tsai, pp431-454 (1979)

[7] J.M.Whitney, ASTM STP 813, T.K.O'Brien, Ed., pp225-245 (1983)

[8] SV.Ramani and DP.Williams, Notched and Unnotched Fatigue Behaviour of Angle-Ply Graphite /Epoxy Composites, ASTM STP 638, pp27-46 (1987)

[9] C.Bathias, Advances in Fatigue Science and Technology, C.MouraBranco and L.Guerra Rosa Eds., by Kluwer Academic Publishers, pp659-676 (1989)

[10] H.T.Hahn, R.Y.Kim,, J. Composite Materials, vol.10, pp156-180 (1976)

[11] T.K.O'Brien and K.L.Reifsnider, J. Composite Materials, vol.15, pp55-70 (1981)

[12] C.E.Bakis and W.W.Stinchcomb, ASTM STP 907, H.T.Hahn, Ed., pp314-334 (1986)

[13] A.Razavan et al, J. Composite Technology \& Research, vol.10, No.1, pp3-10 (1988)

[14] R.A.Simonds et al, ASTM STP 1012, Paul A. Lagace, Ed., pp5-18 (1989)

[15] J.Y.Xiao and C.Bathias: Fatigue damage mechanisms of woven laminates, 9th ICCM,Madrid (1993)

[16] J.Y.Xiao and C.Bathias: Fatigue behavior of unnotched and notched woven Glass /Epoxy Laminates, accepted by Composites Science and Technology, to be published 